\title{
ОСОБЛИВОСТІ ЕМОЦІЙНО-ПОВЕДІНКОВИХ РЕАКЦЙ У ЩУРІВ ПРИ МОДЕЛЮВАННІ В НИХ СИНДРОМУ АПНОЕ СНУ
}

\section{Особливості емоційно-поведінкових реакцій у щурів при моделюванні в них синдрому апное сну \\ Р. Е. Солтані \\ Тернопільський національний медичний університет імені І. Я. Горбачевського мОЗ України}

Резюме. Синдром обструктивного апное-гіпопное під час сну (СОАГС) - патологічний стан зупинки вентиляції легенів у хворих понад 10 с; при цьому протягом 7- годинного сну апное-гіпопное реєструється не менше 30 разів. Він зумовлений періодичною обструкцією верхніх дихальних шляхів на рівні горла; при цьому на тлі збереження дихальних зусиль призупиняється легенева вентиляція та понижується насиченість крові киснем; у пацієнтів виникає груба оррагментація сну та надмірна денна сонливість. У хворих спостерігається суттєве погіршення якості життя, зумовлене інсомнічними розладами, та розвивається при цьому симптомокомплекс органічних порушень. Для глибшого вивчення патогенетичних механізмів СОАГС доцільно використовувати експериментальні моделі на дрібних лабораторних тваринах.

Мета дослідження - оцінити особливості емоційно-поведінкових реакцій у щурів при моделюванні в них синдрому апное сну.

Матеріали і методи. Дослідження проведено на 42-х білих безпородних щурах-самцях, які перебували на звичайному харчовому раціоні віварію. Для виключення випадкових впливів усі тварини перебували в однакових умовах і брали їх для досліду в один і той же час. 3 метою усунення коливань гормонального фону для експерименту брали нелінійних білих статевозрілих щурів-

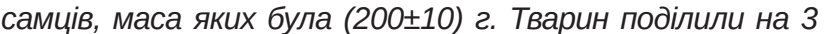
групи: першу - щури, у яких під барбітуровим наркозом моделювали синдром обструктивного апное-гіпопное сну (21 тварина), друга - щури, яким проводили барбітуровий наркоз (14 тварин), третя - інтактні тварини (7 щурів). Забезпечували тваринам медикаментозний сон, вводячи їх у наркоз. Для цього використовували 1\% розчин натрію тіопенталу. Анестетик у дозі 60 мг/кг вводили внутрішньочеревно у ділянку гіпогастрію. Тварини інтактної групи отримували внутрішньочеревно еквівалентну кількість ізотонічного розчину $\mathrm{NaCl}$. Проводили дослідження фрізіологічної активності шурів за тестом Буреша у відкритому полі. Досліджували особливості емоційно-поведінкових реакцій у тварин, яким моделювали синдром обструктивного апное-гіпопное сну. Для цього сконструювали пристрій, який за допомогою елек-
Peculiarities of emotional-behavioral reactions in rats with simulating apnea sleep syndrome

\section{R. E. Soltani}

I. Horbachevsky Ternopil National Medical University

e-mail: soltani@tdmu.edu.ua

Summary. Obstructive sleep apnea-hypopnea syndrome (OSAHS) - a pathological condition of pulmonary ventilation in patients over 10 seconds; during 7 hours of sleep apnea-hypopnea is registered at least 30 times. It is caused by periodic obstruction of the upper respiratory tract at the level of the throat; at the same time against the background of preservation of respiratory efforts the pulmonary ventilation is suspended and oxygen saturation of blood decreases; patients experience gross sleep fragmentation and excessive daytime sleepiness. Patients have a significant deterioration in quality of life due to insomnia disorders, and develop a symptom complex of organic disorders. For a deeper study of the pathogenetic mechanisms of OSAHS, it is advisable to use experimental models on small laboratory animals.

The aim of the study - to evaluate the features of emotional and behavioral reactions in rats when simulating their sleep apnea syndrome.

Materials and Methods. The study was performed on 42 white outbred male rats that were on a regular vivarium diet. To exclude accidental influences, all animals were in the same conditions and entered the experiment at the same

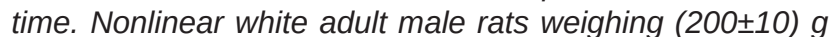
were taken for the experiment in order to eliminate the fluctuations of the hormonal background. The animals were divided into 3 groups: I - rats which under barbiturate anesthesia were simulated obstructive sleep apnea (21 rats), II - rats, which underwent barbiturate anesthesia (14 rats), III - intact animals (7 rats). The animals were provided with medicated sleep by anesthesia. $1 \%$ thiopental sodium solution was used for this purpose. Anesthetic at a dose of $60 \mathrm{mg} / \mathrm{kg}$ was injected intraperitoneally into the hypogastric area. Animals of the intact group received an intraperitoneally equivalent amount of isotonic $\mathrm{NaCl}$ solution. The physiological activity of rats was studied by the Buresh test in the open field. The features of emotional and behavioral reactions in animals, which simulated the syndrome of obstructive sleep apnea-hypopnea were investigated. To do this, a device was constructed which, with the help of an electromagnetic shutter, causes the two straps to be closed in time, between which a latex thin- 
тромагнітного затвору викликає дозоване за часом змикання двох планок, між якими фріксується латексна тонкостінна муфрта, одягнута на мордочки тварин, проксимальна частина яких щільно прилягає до шкіри голови. Тварини при цьому знаходились у медикаментозному сні. Дослідження проведено на 4; 12 і 18 доби.

Результати. Під час моделювання інспіраторного апное внутрішньоплевральний тиск у них зростав у 5-6 разів. Досліджували емоційно-поведінкові реакції у 42 щурів за тестом «відкрите поле» 3 інтервалом у 3 дні, загальною тривалістю 18 днів. Виявили погіршення значень горизонтальної та вертикальної активності й показників вегетативного балансу на тлі проведеного наркозу та, особливо, при моделюванні у них синдрому обструктивного апное сну, що засвідчувало їхню здатність до погіршення адаптації, на відміну від інтактних тварин.

Висновки. Для поглибленого вивчення феномену обструктивного апное-гіпопное сну доцільно застосовувати запропоновану експериментальну модель інспіраторного перекриття ротового та носових просвітів тварин на $(2,2 \pm 0,2)$ с протягом кожної хвилини сну під час наркозу. При моделюванні обструктивного апное-гіпопное сну в щурів відбуваються функціональні зміни - пониження емоційно-поведінкових реакцій та вегетативного балансу, що вказує на виражені порушення адаптаційних механізмів.

Ключові слова: синдром апное сну; експеримент; емоційно-поведінкові реакції у щурів.

\section{ВСТУП}

Синдром обструктивного апное-гіпопное під час сну (СОАГС) - патологічний стан зупинки вентиляції легенів у хворих понад 10 с; при цьому протягом 7-годинного сну апное-гіпопное реєструється не менше 30 разів [1, 2]. Він зумовлений періодичною обструкцією верхніх дихальних шляхів на рівні горла; при цьому на тлі збереження дихальних зусиль призупиняється легенева вентиляція та понижується насиченість крові киснем; у пацієнтів виникає груба фррагментація сну та надмірна денна сонливість [3]. За останні 50 років значно зросла кількість випадків хворих із СОАГС у світі [4]. Вивченням даного питання займаються вчені різних країн [5-8]. У хворих спостерігається суттєве погіршення якості життя, зумовлене інсомнічними розладами, та розвивається при цьому симптомокомплекс органічних порушень [9-12]. Для глибшого вивчення патогенезу даного захворювання доцільним є його вивчення в експерименті на дрібних лабораторних тваринах. Дослідження СОАГС у тварин у доступній нам літературі немає.

Метою дослідження було оцінити особливості емоційно-поведінкових реакцій у щурів при моделюванні в них синдрому апное сну.

МАТЕРІАЛИ I МЕТОДИ. Дослідження проведено на 42-х білих безпородних щурах-самцях, walled coupling is fixed, worn on the muzzles of animals, the proximal part of which is close to the scalp. The animals were in a medicated sleep. The study was conducted on 4, 12 and 18 days.

Results. During the simulation of inspiratory apnea, their intrapleural pressure increased 5-6 times. We studied the emotional and behavioral responses of 42 rats on the test "open field" with an interval of 3 days, a total duration of 18 days. Deterioration of values of horizontal and vertical activity and indicators of vegetative balance on the background of anesthesia and, especially, in the simulation of obstructive sleep apnea syndrome, which showed their ability to impair adaptation, in contrast to intact animals.

Conclusions. For in-depth study of the phenomenon of obstructive sleep apnea-hypopnea, it is advisable to apply the proposed experimental model of inspiratory overlap of the oral and nasal lumens of animals for (2.2 \pm 0.2$)$ second during each minute of sleep during anesthesia. When modeling obstructive sleep apneahypopnea in rats there are functional changes - a decrease in emotional and behavioral responses and autonomic balance, which indicates a pronounced violation of adaptive mechanisms.

Key words: sleep apnea syndrome; experiment; emotional and behavioral reactions in rats.

які перебували на звичайному харчовому раціоні віварію. Для виключення випадкових впливів усі тварини перебували в однакових умовах і брали їх у дослід в один і той же час: при температурі 20-22 ${ }^{\circ} \mathrm{C}$, вологості повітря 50-60 \%, у період $315^{00}$ до $17^{00}$ год. У вільний від досліджень час тварини перебували у звичайних умовах віварію на збалансованому харчовому раціоні відповідно до діючих норм.

3 метою усунення коливань гормонального фону для експерименту брали нелінійних білих

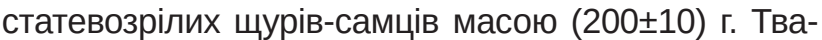
рин поділили на 3 групи: перша - щури, у яких під барбітуровим наркозом моделювали синдром обструктивного апное-гіпопное сну (21 тварина), друга - щури, яким проводили барбітуровий наркоз (14 тварин), третя - інтактні тварини (7 щурів). Забезпечували тваринам медикаментозний сон, вводячи їх у наркоз. Для цього використовували 1\% розчин натрію тіопенталу. Анестетик у дозі 60 мг/кг вводили внутрішньочеревно у ділянку гіпогастрію. Тварини інтактної групи отримували внутрішньочеревно еквівалентну кількість ізотонічного розчину $\mathrm{NaCl}$.

Під час роботи з лабораторними тваринами дотримувались правил гуманного відношення до експериментальних тварин та вимог, затверджених комітетом з біоетики Тернопільського національного медичного університету імені І. Я. Горбачевського МОЗ України; Міжнародних вимог про гуманне 
поводження 3 тваринами згідно 3 Європейською конвенцією захисту хребетних тварин, що використовуються для дослідних та інших наукових цілей; методичних рекомендацій ДФЦ МОЗ України «Доклінічні дослідження лікарських засобів» [13].

Проводили наступні дослідження: фрізіологічної активності щурів за тестом Буреша у відкритому полі [14] та морфологічні - масометричну характеристику серця та окремих його частин [57].

Статистичну обробку циорових даних виконано за допомогою програмного забезпечення Excel (Microsoft, США) та STATISTICA 6.0 (Statsoft, США).

\section{РЕЗУЛЬТАТИ Й ОБГОВОРЕННЯ}

Під наркозом щурам проводили пункцію плевральної порожнини та вимірювали у них внутрішньоплевральний тиск (рис. 1). Для цього дистальний кінець катетера, приєднаний до голки, якою проводили плевральну пункцію, опускали у ємність, заповнену водним розчином фурациліну. Зріз катетера підносили до поверхні розчину, ледь її торкаючись. Завдяки своєму забарвленню, розчин фрурациліну можна було візуалізувати через прозорі стінки катетера.

Виявили, що під час звичайного (не утрудненого) дихання стовпчик рідини у катетері коливався синхронно частоті руху грудної клітки; амплітуда його була $(1,5 \pm 0,3)$ мм: під час вдиху до мінус 1,5 мм вод. ст., а під час видиху - до 0 мм вод. ст.

В іншій серії експерименту в щурів під наркозом моделювали синдром сонного апное, щільно перекриваючи латексною мембраною, змодельованою у вигляді конуса, верхні дихальні шляхи на рівні носа та рота тривалістю 6-7 с (рис. 2).

Виявили, що на фразі вдиху рівень стовпчика розчину фрурациліну піднімався до мінус $(8,7 \pm 0,5)$ мм вод. ст., а на фразі видиху - до 0 мм вод. ст. Під час такої затримки дихання спостерігали виражену синюшність шкіри тварин; фрізіологічне забарвлен-

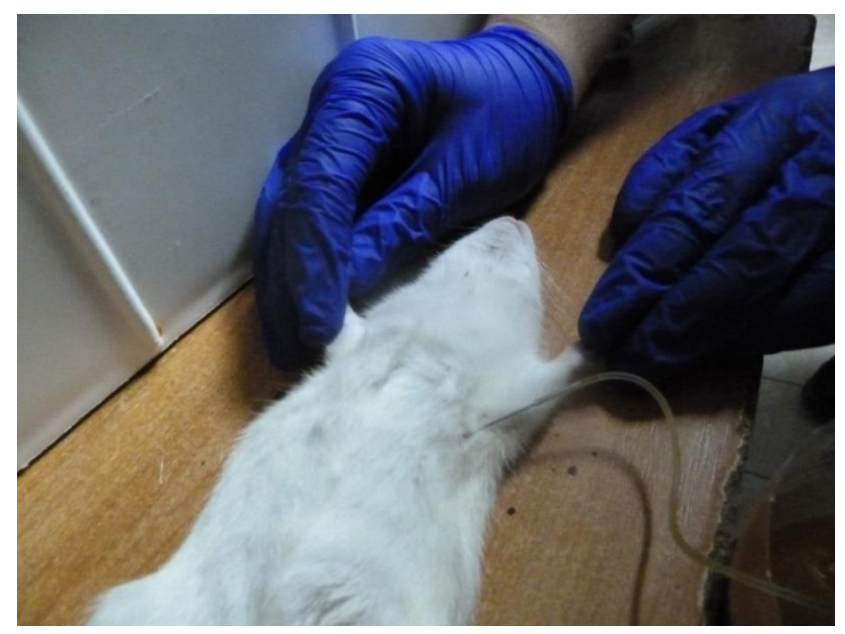

Рис. 1. Вимірювання у щура внутрішньоплеврального тиску під час звичайного дихання. ня шкіри відновлювалось протягом наступних 3-4 хв звичайного дихання.

Таким чином, у ході експерименту ми установили, що при модельованому інспіраторному закритті дихальних шляхів внутрішньоплевральний тиск змінюється (з від'ємним знаком) у 5-6 разів. Під час такого перепаду тиску відповідно збільшується й присмоктувальна дія грудної клітки на кровотік, що безпосередньо впливає на роботу серця.

При моделюванні синдрому обструктивного апное сну тваринам під наркозом одягали на мордочки латексні тонкостінні муфрти, проксимальна частина яких щільно прилягала до шкіри голови.

Дистальну, виступальну частину муфти виводили крізь отвір пластикового контейнера, у який поміщали щура у стані наркотичного сну. Потім дистальну (вільну) частину латексної мусрти проводили між двома дерев'яними рейками, одна із яких (нижня) була фріксованою, а друга (верхня) мала змогу вільно пересуватись у вертикальному напрямку від 0 мм (при зімкнутих рейках) до 15 мм (при їхньому максимальному розведенні).

Рушійною силою, яка забезпечувала піднімання верхньої рейки та утворення між ними просвіту, був електромагнітний затвор.

Циклічність та рівномірність чергувань відкривання та змикання просвіту між рейками забезпечував модифікований роликовий насос, який можна було установити на будь-яку швидкість (від 1 до 999 обертів на хвилину).

Таким чином, ми одночасно укладали в ряд по 7 тварин у стані наркозу, яким проводили моделювання синдрому обструктивного сонного апное способом викликання асфіксії унаслідок перекриття ротового та носового просвітів (рис. 3, 4).

Експериментальним шляхом ми розрахували,

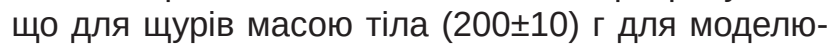
вання СОАГС найоптимальнішим за часом виявився інтервал апное у 2,0-2,5 с (що еквівалент-

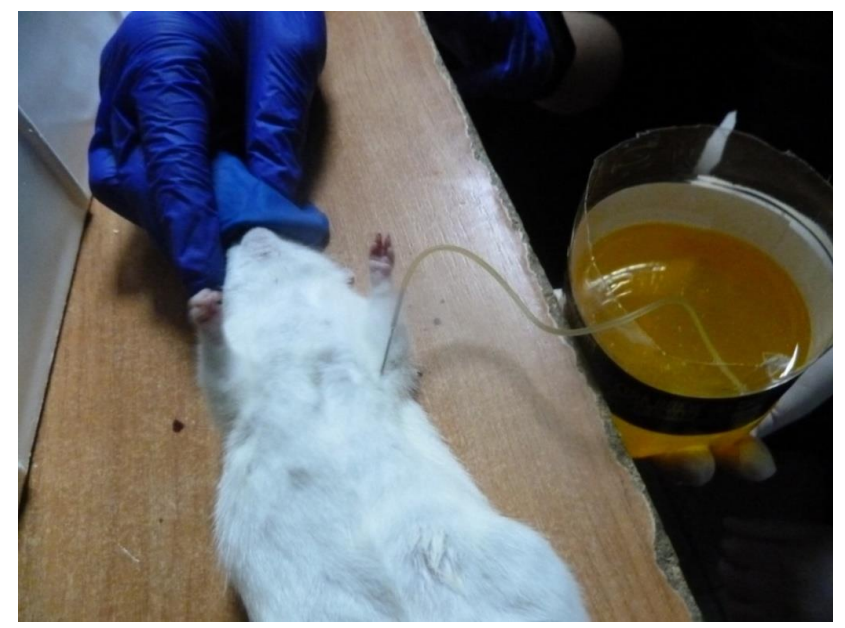

Рис. 2. Вимірювання у щура внутрішньоплеврального тиску при моделюванні синдрому обструктивного апное-гіпопное сну.
Вісник медичних і біологічних досліджень Bulletin of Medical and Biological Research 


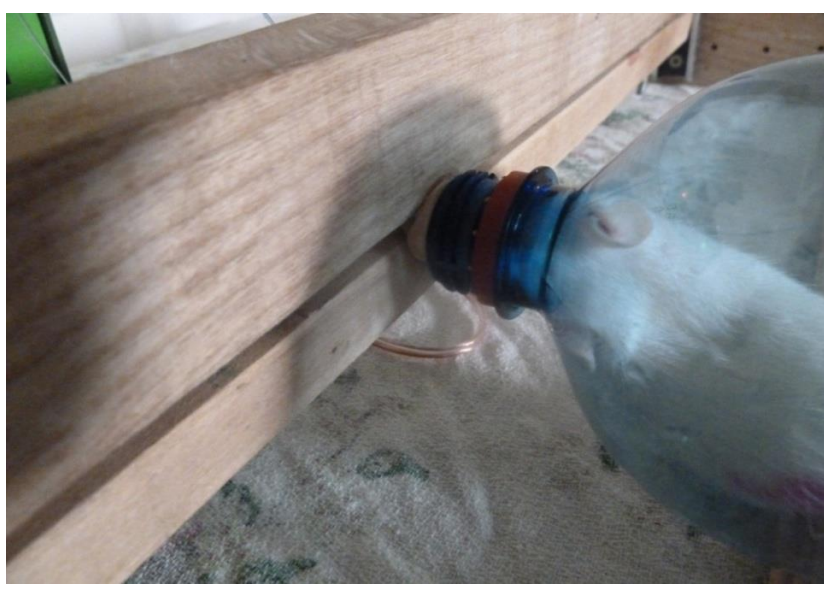

Рис. 3. Моделювання у щура синдрому обструктивного апное сну способом перекривання дихальних шляхів.

но зупинці дихання у дорослої людини тривалістю 15-20 c).

Експеримент у вигляді періодичної ассріксії тривав протягом часу знаходження тварин у наркозі. Після пробудження від наркозу експеримент припиняли, і щури продовжували дихати звичайним способом. Характерно, що кожне наступне введення тварини у наркоз потребувало збільшення дози анестетика: 65 мг/кг, 70 мг/кг, 75 мг/кг і т. д.

В якості групи контролю використовували другу групу щурів, яких вводили у наркоз, однак порушень дихання у них не викликали. Третю групу щурів (контрольну) склали інтактні тварини.

Експеримент проводили 3 інтервалом у 3 доби загальною тривалістю 18 діб.

Емоційно-поведінкові реакції у щурів. Зміни поведінкової реакції тварин є інтегральним показником їхньої реакції на стрес. Вважається, що час-

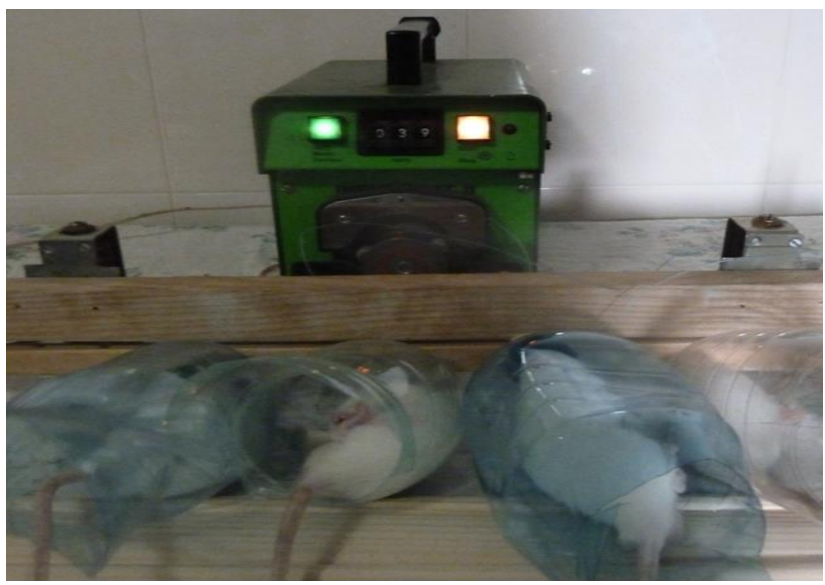

Рис. 4. Щури в експерименті: моделювання у них синдрому обструктивного апное сну.

тота десекацій відображає емоційність тварин, а локомоторні реакції - їхню дослідницьку та рухову активність [15].

У щурів оцінювали орієнтувально-пошукову та емоційну активності за тестом «відкрите поле» [16] на 4-ту, 12-ту та 18-ту добу експерименту (табл.). Такі інтервали вибрано для того, що у цей час найбільш виражено можна оцінити наступні стадії: тривоги, резистентності та виснаження загального адаптаційного синдрому [14].

Для аналізу поведінкових реакцій використовували нейрофрізіологічні показники: горизонтальної рухової активності (кількість перетнутих квадратів), вертикальної активності (кількість стійок), кількість оглянутих нірок); для оцінювання вегетативного балансу - кількість умивань (грумінг) і актів дефекацій (кількість болюсів та сечовипускання) [4]. Тривалість спостереження становила 3 хв.

Таблиця. Емоційно-поведінкові реакції щурів при моделюванні у них синдрому обструктивного апное-гіпопное сну $(\mathrm{M} \pm \mathrm{M})$

\begin{tabular}{|c|c|c|c|c|c|c|}
\hline \multirow{3}{*}{ Група тварин } & \multirow{3}{*}{$\begin{array}{l}\text { Доба спосте- } \\
\text { реження }\end{array}$} & \multicolumn{5}{|c|}{ Прояви емоційно-поведінкових реакцій } \\
\hline & & \multicolumn{3}{|c|}{$\begin{array}{c}\text { рухова активність та дослідницька } \\
\text { поведінка }\end{array}$} & \multicolumn{2}{|c|}{$\begin{array}{c}\text { показники вегетативного } \\
\text { балансу }\end{array}$} \\
\hline & & ГРА & BPA & $\begin{array}{c}\text { зазирання } \\
\text { у нірку }\end{array}$ & $\begin{array}{l}\text { кількість реакцій } \\
\text { грумінга }\end{array}$ & $\begin{array}{l}\text { кількість } \\
\text { болюсів }\end{array}$ \\
\hline \multirow{3}{*}{$\begin{array}{l}\text { Інтактні тварини, } \\
\text { третя група } \\
(\mathrm{n}=7)\end{array}$} & 4-та & $14,12 \pm 0,66$ & $3,77 \pm 0,43$ & $8,62 \pm 0,65$ & $0,92 \pm 0,35$ & 0 \\
\hline & 12-та & $12,77 \pm 0,58$ & $3,50 \pm 0,36$ & $8,40 \pm 0,55$ & $1,30 \pm 0,44$ & $0,22 \pm 0,10$ \\
\hline & 18-та & $11,50 \pm 0,0,77$ & $3,03 \pm 0,68$ & $7,93 \pm 0,53$ & $1,20 \pm 0,43$ & $0,1 \pm 0,1$ \\
\hline \multirow{3}{*}{$\begin{array}{l}\text { Тварини, яким прово- } \\
\text { дили наркоз, } \\
\text { друга група } \\
(\mathrm{n}=14)\end{array}$} & 4-та & $6,80 \pm 0,43^{\text {** }}$ & $1,03 \pm 0,41^{*}$ & $1,50 \pm 0,62^{*}$ & $1,00 \pm 0,0,44$ & $0,40 \pm 0,22$ \\
\hline & 12-та & $5,30 \pm 0,43^{* *}$ & $0,97 \pm 0,22^{\star *}$ & $2,02 \pm 0,33^{*}$ & $0,42 \pm 0,31$ & $0,20 \pm 0,14$ \\
\hline & 18-та & $4,33 \pm 0,63^{*}$ & $1,03 \pm 0,24^{*}$ & $0,50 \pm 0,44^{*}$ & $1,55 \pm 0,23$ & $0,50 \pm 0,4$ \\
\hline \multirow{3}{*}{$\begin{array}{l}\text { Тварини, яким під } \\
\text { наркозом моделювали } \\
\text { СОАГС, } \\
\text { перша група } \\
(\mathrm{n}=21)\end{array}$} & 4-та & $3,04 \pm 0,44^{\star \star}$ & $0,55 \pm 0,34^{\star \star}$ & $1,54 \pm 0,33^{\star \star}$ & $0,46 \pm 0,34$ & $0,84 \pm 0,35^{\star}$ \\
\hline & 12-та & $2,34 \pm 0,35^{\star \star}$ & $0,22 \pm 0,12^{\star \star}$ & $0,84 \pm 0,34^{\star \star}$ & $1,55 \pm 0,33$ & $0,44 \pm 0,22$ \\
\hline & 18-та & $1,02 \pm 0,33^{\star \star}$ & $0,13 \pm 0,15^{\star \star}$ & $0,55 \pm 0,20^{\star \star}$ & $2,31 \pm 0,36^{*}$ & $0,54 \pm 0,12^{*}$ \\
\hline
\end{tabular}

Примітка. * - p<0,05, * - p<0,01 порівняно з показниками в інтактних тварин у ті ж самі часові проміжки. 
Завдяки такій методиці можливо було одночасно досліджувати рухову та дослідницьку активність і вегетативно-емоційний стан тварин [13].

Для запобігання впливу відволікаючих фракторів після кожної тварини поверхню поля обробляли $70 \%$ розчином етанолу.

Результати дослідження засвідчили, що після проведення щурам повторного наркозу та, особливо, при моделюванні у них обструктивного сонного апное виникала суттєва зміна фрізіологічного стану. В тварин спостерігали пригнічення поведінкових реакцій унаслідок погіршення фрізичного стану (апатія, млявість, тахікардія, зниження рухової активності, дисорункція сечового міхура). Серед тварин першої групи померло 7 тварин (33,3%), другої - 2 щури (14,3 \%).

Маса контрольних та експериментальних тварин протягом експерименту не відрізнялась і ста-

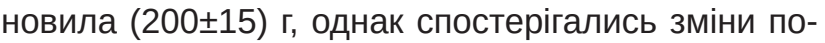
ведінкових реакцій, що проявлялися у зниженні локомоторної та дослідницької активності (пере-

\section{СПИСОК ЛІТЕРАТУРИ}

1. Синдром обструктивного апноэ/гипопноэ сна: критерии степени тяжести, патогенез, клинические проявления и методы диагностики / О. В. Алексеева, Н. А. Шнайдер, И. И. Демко, М. М. Петрова // Сибирский медицинский жуонал (Иркутск). - 2016. - № 1. - С. 91-97.

2. Residual sleepiness in sleep apnea patients treated by continuous positive airway pressure / M. Gasa, R. Tamisier, S. H. Launois [et al.] // Journal of Sleep Research. - 2013. - Vol. 22 (4). - P. 389-397.

3. Синдром обструктивного апное сну: зв'язок із серцево-судинними захворюваннями та основні методи діагностики / В. Г. Лизогуб, О.В.Савченко, Т. В. Завальська [та ін.] // Лікарська справа. Врачебное дело. - 2012. № 1/2. - C. 45-56.

4. Mbata G. C. Obstructive sleep apnea hypopnea syndrome / G. C. Mbata, J. C. Chukwuka // Ann. Med. Health Sci. Res. - 2012. - Vol. 2 (1). - P. 74-77.

5. Lerousseau L. Sleepiness, continuous positive airway pressure and the obstructive sleep apnea hypopnea syndrome / L. Lerousseau // Rev. Mal. Respir. - 2018. Vol. 35 (2). - P. 116-133.

6. Stöwhas A.-C. Obstructive sleep apnea syndrome / A.-C. Stöwhas, M. Lichtblau, K. E. Bloch // Praxis (Bern 1994). - 2019. - Vol. 108 (2). - P. 111-117.

7. Continuous positive airway pressure intolerance associated with elevated nasal resistance is possible mechanism of complex sleep apnea syndrome / C. Nakazaki, A. Noda, Y. Yasuda [et al.] // Sleep Breath. 2012. - Vol. 16 (3). - P. 747-752.

8. A singular oral appliance to treat obstructive sleep apnea in CPAP non-adherent patients / D. F. Barbosa, L. C. Giannasi, L. M. D. B. Ferreira [et al.] // Dental Press J. Orthod. -2020. - Vol. 25 (5). - P. 44-50. тинання ліній, заглядання у нірки, завмиранням у кутах та підвищення кількості болюсів).

Погіршення значень горизонтальної та вертикальної активності й показників вегетативного балансу щурів на тлі проведеного наркозу та, особливо, при моделюванні у них сидрому обструктивного апное засвідчувало їхню здатність до погіршення адаптації, на відміну від інтактних тварин.

\section{ВИСНОВКИ}

Для поглибленого вивчення френомену обструктивного апное-гіпопное сну доцільно застосовувати запропоновану експериментальну модель інспіраторного перекриття ротового та носових просвітів тварин на $(2,2 \pm 0,2)$ с протягом кожної хвилини сну під час наркозу.

При моделюванні обструктивного апное-гіпопное сну в щурів відбуваються фрункціональні зміни - пониження емоційно-поведінкових реакцій та вегетативного балансу, що вказує на виражені порушення адаптаційних механізмів.

9. Obstructive sleep apnea: neurocognitive and behavioral functions before and after treatment / K. Turner, E. Zambrelli, S. Lavolpe [et al.] // Funct. Neurol. - 2019. Vol. 34 (2). - P. 71-78.

10. Seda G. Effect of obstructive sleep apnea on neurocognitive performance / G. Seda // Sleep Med. Clin. 2020. - Vol. 15 (1). - P. 77-85.

11. Obstructive sleep apnea syndrome and the quality of life / A. C. Coman, C. Borzan, C. S. Vesa, D. A. Todea // Clujul. Med. - 2016. - Vol. 89 (3). - P. 390-395.

12. Sleepiness, fatigue, anxiety and depression in chronic obstructive pulmonary disease and obstructive sleep apnea - overlap - syndrome, before and after continuous positive airways pressure therapy / N. T. Economou, I. Ilias, L.Velentza [et al.] // PLoS One. - 2018. - Vol. 13(6). P. e0197342.

13. Стефранов О.В. Доклінічні дослідження лікарських засобів: метод. реком. // К.: Авіценна, 2001. $528 \mathrm{c}$.

14. Буреш Я. Методики и основные эксперименты по изучению мозга и поведения / Я. Буреш, О. Бурешова, Дж.П. Хьюстон. - М. : Высшая школа, 1991. - 527 с.

15. Маркель А. Л. Метод комплексной регистрации поведенческих и вегетативных реакций у крыс при проведении теста открытого пол / А. Л. Маркель, Р. А. Хусаинов // Журнал высшей нервной деятельности . - 1976. -26 , № 6. - C. 13-14.

16. Тозюк О. Ю. Характеристика емоційно-поведінкових реакцій щурів в умовах хронічного імобілізаційного стресу на тлі дії похідного 5-г-тіо-тетразоло [1,5-c] хіназоліну / О. Ю. Тозюк // Запорожский медицинский журнал. - 2013. - № 5. - С 57-59. 


\section{REFERENCES}

1. Alekseeva OV, Shajder NA, Demko II, Petrova MM. [Obstructive sleep apnea/hypopnea syndrome: Severity criteria, pathogenesis, clinical manifestations and diagnostic methods]. Sibirskiy meditsinskiy zhurnal (Irkutsk). 2016;1: 91-7. Russian.

2. Gasa M, Tamisier R, Launois SH, Sapene M, Martin F, Stach B, Grillet Y, Levy P, Pepin JL. Residual sleepiness in sleep apnea patients treated by continuous positive airway pressure. Journal of Sleep Research, 2013;22(4): 389-397.

3. Lyzohub VH, Savchenko OV, ZavalskaTV, DykukhaIC, Lozyuk MO. [Obstructive sleep apnea syndrome : connection with cardiovascular diseases and basic diagnostic methods]. Likarska sprava. Vrachebnoe delo. 2012;1/2: 45-56. Ukrainian.

4. Mbata GC, Chukwuka JC. Obstructive sleep apnea hypopnea syndrome. Ann Med Health Sci Res. 2012;2(1): 74-7.

5. Lerousseau L. Sleepiness, continuous positive airway pressure and the obstructive sleep apnea hypopnea syndrome]. Rev Mal Respir. 2018;35(2): 116-33. Available from: https://www.ncbi.nlm.nih.gov/nlmcatalog?term=\%2 2Rev+Mal+Respir\%22\%5BTitle+Abbreviation\%5Dhttps:// pubmed.ncbi.nlm.nih.gov/29454715/.

6. Stöwhas A-C, Lichtblau M, Bloch KE. Obstructive sleep apnea syndrome. Praxis (Bern 1994). 2019;108(2): 111-7. Available from: https://www.ncbi.nlm.nih.gov/nl mcatalog?term $=\% 22$ Praxis+\%28Bern+1994\%29\%22\% 5BTitle+Abbreviation\%5Dhttps://pubmed.ncbi.nlm.nih. gov/30722731/

7. Nakazaki C, Noda A, Yasuda Y, Nakata S, Koike Y, Yasuma F, Murohara T, Nakashima T. Continuous positive airway pressure intolerance associated with elevated nasal resistance is possible mechanism of complex sleep apnea syndrome. Sleep Breath. 2012;16(3): 747-52.
8. Barbosa DF, Giannasi LC, Ferreira LMDiB, Cruz MMe, Alves MC, Berzin F. A singular oral appliance to treat obstructive sleep apnea in CPAP non-adherent patients. Dental Press J Orthod. 2020;25(5): 44-50.

9. Turner K, Zambrelli E, Lavolpe S, Baldi C, Furia F, Canevini MP. Obstructive sleep apnea: neurocognitive and behavioral functions before and after treatment. Funct Neurol. 2019;34(2): 71-8.

10. Seda G, Han TS. Effect of obstructive sleep apnea on neurocognitive performance. Sleep Med Clin. 2020;15(1): 77-85.

11. Coman AC, Borzan C, Vesa CS, Todea DA. Obstructive sleep apnea syndrome and the quality of life. Clujul. Med. 2016;89(3): 390-5.

12. Economou NT, Ilias I, Velentza L, Papachatzakis Y, Zarogoulidis P, Kallianos A, Trakada G. Sleepiness, fatigue, anxiety and depression in chronic obstructive pulmonary disease and obstructive sleep apnea - overlap - syndrome, before and after continuous positive airways pressure therapy. PLoS One. 2018;13(6): e0197342.

13. Srefanov OV. Preclinical studies of medications: a method. rekom. [Доклінічні дослідження лікарських засобів: метод. реком.] Kyiv: Avitsenna; 2001. Ukrainian.

14. Buresh Ya, Bureshova O, Khyuston JP. Techniques and basic experiments to study the brain and behavior. [Meтодики и основные эксперименты по изучению мозга и поведения] Moscow: Vysshaya shkola; 1991. Russian.

15. Markel AL, Khusainov RA. [Method of complex registration of behavioral and autonomic reactions in rats during the open field test]. 1976;26(6): 1314. Russian.

17. Tozyuk OYu. [Characteristics of emotional and behavioral reactions of rats under conditions of chronic immobilization stress against the background of the action of a derivative of 5-r-thio-tetrazolo [1,5-c] quinazoline]. Zaporizkyi med zhurn. 2013;5: 57-9. Ukrainian. 